\title{
ESCRAVIDÃO E LIBERDADE NAS AMÉRICAS: UM CONVITE À RENOVAÇÃO HISTORIOGRÁFICA
}

FREIRE, Jonis; e SECRETO, María Verónica (orgs.). Formas de liberdade: gratidão, condicionalidade e incertezas no mundo escravista nas Américas. Rio de Janeiro: Mauad/Faperj, 2018. 272p.

$O$

livro aqui resenhado reúne textos de especialistas de diferentes países a respeito da experiência da escravidão e da liberdade na América Latina e Caribe. Com alguma variação de abordagem, estilo e perspectiva, os trabalhos transitam entre a história social e a micro-história, explorando uma rica documentação de natureza administrativa, eclesiástica, legislativa, judiciária e notarial. O livro é composto por nove capítulos que se estendem espacialmente pelo Caribe francês, por diferentes regiões da América hispânica, de norte a sul do continente, e pelo Brasil, concentrando-se de modo preponderante nos séculos XVIII e XIX. Alguns são escritos em espanhol, outros em português.

O primeiro capítulo, "El periplo de Víctor Chappotín, de nación lucumí, desde Saint-Domingue a la Cuba plantacionista: esclavitud, autonomía y propiedad (1797-1841)", é da lavra de Aisnara Perera Díaz e María de los Ángeles Meriño Fuen- tes. O ponto de destaque é a mobilidade geográfica e social de Víctor Chappotín, um africano de nação lucumí ${ }^{1}$ que viveu como escravo a convulsão revolucionária da colônia francesa de Saint-Domingue, futuro Haiti, na década de 1790 , indo parar em Cuba junto com milhares de outros refugiados após uma breve estância em Trinidad de Barlovento. Como revela seu testamento, Víctor, que se tornou forro apenas dois anos antes de morrer, adquiriu cinco escravos quando ainda era cativo. $\mathrm{O}$ fio condutor do capítulo é justamente elucidar as condições concretas que permitiram a esse indivíduo a façanha de ter se tornado um escravo-senhor, para além das questões

1 A designação lucumí corresponde a pessoas escravizadas falantes do iorubá procedentes da Baía do Benin desembarcadas em colônias espanholas, marcadamente em Cuba. Os lucumís são frequentemente associados aos nagô do Brasil. Cf. David Eltis, "A diáspora dos falantes de iorubá, 1650-1865: dimensões e implicações", Topoi, v. 7, n. 13 (2006), pp. 271-299. 
formais em torno de sua capacidade jurídica. ${ }^{2}$ As raízes da explicação delineada no estudo repousam na fidelidade para com o antigo senhor, don Francisco de Chappotín Guzmán, a quem acompanhou desde a fuga deste de Saint-Domingue, e no papel ativo que desempenhou na montagem de plantações de café em terras cubanas: existiria uma sólida relação de reciprocidade ali estabelecida. Pelas evidências levantadas, à diferença dos que cerraram fileiras ao lado de Toussaint L'Ouverture, líder da revolução haitiana, o protagonismo de Víctor se deu pela via do engajamento direto com a reprodução do sistema de escravidão. Perera e Meriño tomam esse caso como uma porta de entrada para o contexto mais amplo de transformações ambientais, econômicas e sociais do período e, por conseguinte, para o campo de possibilidades aberto a indivíduos como Victor Chappotin (pp. 18-19).

Em "“Eles não são livres, e eles não têm senhores; eles não são escravos, e eles não são cidadãos': liberdade precária e clandestina no Caribe francês (Martinica, século XIX)", Letícia Gregório Canelas traz um interessante panorama das alforrias no Caribe francês. A autora destaca que a prática da alforria, efetuada, como sabemos, sem reservas significativas nas Américas de co-

2 Sobre casos semelhantes no Brasil, ver Robson Pedrosa Costa, "Escravos senhores de escravos, Pernambuco, séculos XVIII e XIX”, Revista História \& Perspectivas, n. 57 (2018), pp. 149-176. lonização espanhola e portuguesa, sofreu progressiva restrição nas colônias francesas ao longo do século XVIII. A manumissão, como ato privado pelo qual os senhores abriam mão do domínio sobre seus cativos, foi de certo modo descaracterizada pela instituição de uma alforria legal controlada e taxada pesadamente pelo governo colonial, algo que se manteve até 1831. Assim, ainda que os senhores concordassem com a emancipação, os libertos passaram a precisar de uma carta de liberdade autorizada pelo Estado. Consequentemente, além dos dilemas domésticos em torno da alforria, os libertandos passavam a ter que regularizar seu novo status, do que dependia o reconhecimento dos seus direitos. Isto, evidentemente, impôs uma barreira a mais a ser superada, criando uma situação de insegurança que levaria muitos libertos à clandestinidade, como se não bastassem os problemas típicos daquela condição. Para complicar ainda mais, diversas condições legais referentes aos libertos "extraoficiais", por assim dizer, foram surgindo ao longo do tempo, representadas em expressões como se dizendo livre, livre de fato, livre de savana, liberdade estrangeira e patrocinado (pp. 47-48). Dirimindo certa confusão que observa na historiografia, Canelas esclarece o sentido de cada uma daquelas categorias, relacionando-as a circunstâncias sociais específicas. Assim, o trabalho deixa poucas dúvidas sobre a importância de se ter clareza a respeito dos marcos legais das alforrias 
e da situação jurídica das pessoas que as obtinham, aspectos muitas vezes negligenciados ou subestimados pelos pesquisadores. ${ }^{3}$

O terceiro capítulo, "Esclavitud, libertad y status social em Santo Domingo y Puerto Rico durante la diáspora de la Revolución Haitiana", de José Luis Belmonte Postigo, conclui o recorte caribenho do livro. $\mathrm{O}$ texto começa com a forte imagem da chegada de L'Overture a Santiago de los Caballeros, no ano de 1800 , a fim de promover a unificação da ilha de Hispaniola em nome da República francesa, manifestando o clima de indefinição que se instaurava. De forma complementar à discussão aberta no primeiro capítulo, o autor destaca as repercussões do processo revolucionário haitiano em terras espanholas, acompanhando os acontecimentos entre a anexação de Santo Domingo à França e o êxodo subsequente de milhares de pessoas, livres e escravizadas, para outros territórios hispânicos. Diversos impasses surgiram nesse processo migratório. Se os senhores migrantes desejavam manter a todo custo seu patrimônio e sua condição de classe nas novas paragens, o governo colonial e as elites locais buscavam encontrar a fina medida entre o bloqueio do con-

3 De maneira interessante, a historiadora aproxima suas conclusões da história social brasileira, mas uma ausência bibliográfica relevante sobre a Martinica se faz sentir: Dale W. Tomich, Slavery in the Circuit of Sugar: Martinique and the World Economy, 1830-1848, Albany: State University of New York Press, 2016. tágio revolucionário e o estímulo à produção escravista, nem sempre conseguindo consenso sobre como fazê-lo. Em meio a isso, os cativos encontravam tanto novas dificuldades quanto novas possibilidades de negociação e luta. Era um momento crítico de redefinição das fronteiras entre escravidão e liberdade. ${ }^{4}$

$\mathrm{Na}$ sequência, o livro se desloca do Caribe para diferentes jurisdições da América espanhola. "Entre as margens da liberdade. Mulatos livres e negros: condição e experiências diante da justiça eclesiástica (Nova Espanha. Séculos XVII-XVIII)", de Marcelo da Rocha Wanderley e Norma Angélica Castillo, é o capítulo que mais retrocede no tempo. A Nova Espanha é muito mais conhecida entre nós por outras modalidades de exploração do trabalho, como a encomienda e a repartición de índios, mas este capítulo lança luzes sobre a realidade do escravismo mexicano. Os autores analisam demandas judiciais pela liberdade apresentadas à justiça eclesiástica. Os casos analisados diziam respeito basicamente a questões matrimoniais, que revelam uma série de desventuras cotidianas relativas ao exercício da liberdade, incluindo questões de gênero. Além das conclusões objetivas sobre os termos e os resultados dos processos judiciais

4 Sobre o tema, ver Leonardo Marques e Waldomiro L. Silva Junior, "Migrações senhoriais no longo século XIX: comparações, conexões e integrações," Revista de História Comparada, n. 13, (2019), pp. 152-191. 
levantados, o capítulo tece boas reflexões conceituais em torno das relações entre escravidão e liberdade, traz ótimas referências bibliográficas e pondera sobre o senso comum a respeito das taxas elevadas de alforria no mundo hispânico, indicando importantes variações regionais.

Magdalena Candioti é a autora do quinto capítulo do livro, "Manumisiones negociadas y liberdades frágiles en el Río de la Plata. Santa Fe, 1810-1853". Ela destaca que a produção historiográfica sobre as manumissões, bastante robusta para a América Latina em geral, é particularmente restrita para a Argentina, concentrando-se, quando muito, na cidade de Buenos Aires. Contribuindo para suprir essa lacuna, o estudo trata das estratégias de busca pela liberdade e dos percalços enfrentados pelos libertos na cidade interiorana de Santa Fé. Candioti traça um elucidativo histórico do desenvolvimento da escravidão na localidade, articulando-o, ao mesmo tempo, a processos mais amplos relacionados à formação do Estado nacional argentino. A autora fornece um bom panorama estatístico a respeito das modalidades de alforria, assim como da incidência sobre sexo, origem e idade, cruzando questões usuais, sobre a maior taxa de liberdades para as mulheres, por exemplo, com variáveis conjunturais relativos à guerra de independência e a observância de manumissões militares. Ainda, sublinha o recurso a formas ilegais para a emancipação e a utilização da figura de liberto para se referir às crianças nascidas após a decretação da liberdade do ventre, em 1813, o que colaborava para a continuidade de sua exploração.

O sexto capítulo foi escrito por María Verónica Secreto, uma das organizadoras do livro. Intitulado " $\mathrm{O}$ ir e vir dos escravos: as liberdades na Buenos Aires Colonial", o texto começa por problematizar a noção de liberdade, que, a seu juízo, deve ser tratada pelo prisma de sua pluralidade e de seu caráter relativo e indissociável da escravidão, extrapolando seu sentido jurídico estrito. Liberdades, portanto, associadas à eleição de moradia, deslocamento, lazer, negociação, inserção econômica, posse de bens e pecúlio, recurso ao judiciário e às autoridades constituídas em benefício próprio, e assim por diante. Aliado a isso, a autora reivindica o resgate da perspectiva delineada por Emília Viotti da Costa, observando a importância da articulação dialética dessas dimensões da liberdade com fatores relativos ao reino da necessidade, que diz respeito a "condicionantes, circunstâncias, contextos, estruturas, externalidades" (p. 159). ${ }^{5}$ Adentrando em seu recorte propriamente dito, Secreto caracteriza Buenos Aires em fins do século XVIII articulando elementos conjunturais a estratos de longa duração, especialmente do campo do direito, que davam o tom das relações de escravidão na loca-

5 Emília Viotti da Costa, "Novos públicos, novas políticas, novas histórias: do reducionismo econômico ao reducionismo cultural (em busca da dialética)", Revista Anos 90, n. 10 (1998), pp. 7-22. 
lidade. A autora chama atenção para uma questão já bastante discutida para Cuba, que envolve o "direito" de troca de senhores conquistado pelos escravos. ${ }^{6}$ Isto era viabilizado pela obtenção de um papel de venda que podia abrir espaço para a melhoria da condição de vida, o aumento da autonomia ou mesmo a abreviação do caminho para a alforria. Todavia, o ato era atravancado pela resistência senhorial, notadamente quanto à estipulação do preço de venda.

Formas de liberdade é fechado com um último bloco de três capítulos cujo recorte é o Brasil. Roberto Guedes é autor do primeiro deles, "Porque sempre é bom que os forros tenham quem olhe para eles. Benignidade senhorial e libertos submissos na cidade do Rio de Janeiro (primeira metade do século XVIII)". O texto explora os laços de dependência e o fenômeno da submissão contínua de libertos a seus patronos (ex-senhores), algo abordado no livro para o caso hispano-caribenho por Perera Díaz e Meriño Fuentes e Postigo. Guedes amarra bem o objeto ao contexto histórico mais amplo, considerando o fluxo interno e transatlântico do tráfico de escravos, as transformações socioeconômicas do Rio de Janeiro no período e os efeitos da atividade mineradora sobre a cidade. $\mathrm{O}$ autor leva em consideração o cruzamento de valores

6 Alejandro de la Fuente, "Slaves and the Creation of Legal Rights in Cuba: Coartación and Papel". Hispanic American Historical Review, v. 87, n. 4 (2007), pp. 659-692. oriundos da segunda escolástica, que marcaram a chamada monarquia pluricontinental católica, com outros trazidos da África Central pelas vítimas do cativeiro, calcados no reconhecimento de poderes protetores. Para ele, "tais valores influenciaram o comportamento político de escravos e de forros que reconheciam autoridades senhoriais, inclusive as concepções de liberdade de libertos em relação a seus antigos senhores convertidos em patronos" (p. 195). O autor desafia a noção de precariedade tão em voga na historiografia atual, defendendo que a noção de liberdade dependente experimentada por aqueles sujeitos não era percebida como precária. ${ }^{7}$

Em "Africanos-livres emancipados: a construção da liberdade e seus reveses", Jorge Prata de Sousa explora a condição e as experiências dos africanos apreendidos pelas frotas britânicas e brasileiras no período do tráfico ilegal, entre 1831 e 1853. $\mathrm{O}$ autor procede um esclarecimento a respeito da série de tratados que serviram de base para o tratamento daquelas pessoas e assinala a utilização do substantivo composto africanos-livres para dar conta da especificidade de sua condição jurídica. Em síntese, o governo inglês obteve o direito

7 Henrique Espada Lima, "Sob o domínio da precariedade: escravidão e os significados da liberdade de trabalho no século XIX", Topoi, v. 6, n. 11 (2005), pp. 289-326; e Sidney Chalhoub. "Precariedade estrutural: o problema da liberdade no Brasil escravista (século XIX)", História Social, n. 19 (2010), pp. 19-32. 
de inspeção de navios portugueses e mais tarde brasileiros suspeitos de praticarem o comércio negreiro, foram criadas Comissões Mistas e decretada a liberdade para os africanos encontrados em embarcações consideradas boas presas. No entanto, eles ficariam sob a custódia do governo brasileiro por 14 anos, sujeitados à prestação de serviços compulsórios frequentemente facultados a particulares, permanecendo em uma espécie de limbo entre a escravidão e a liberdade. Sousa levanta diversos casos que demonstram como os africanos-livres se valeram de estratégias diversas no cotidiano e buscaram as autoridades para fazer valer seus direitos e efetivar a emancipação após o término do prazo previsto. O capítulo ganharia caso estabelecesse um diálogo explícito com autores como Jaime Rodrigues e Tâmis Parron, que trataram da questão da ilegalidade do tráfico, e com Beatriz Mamigonian, autora do principal livro sobre africanos livres, incluindo, por exemplo, o debate que revisa a noção de que a Lei de 1831, que suprimiu o tráfico, foi apenas "para inglês ver". 8

O capítulo final, "Ser liberta na área mineradora de Rio das Contas - Bahia, século XVIII”, de Kátia

8 Jaime Rodrigues, $O$ infame comércio: propostas e experiências no final do tráfico de africanos para o Brasil (1800-1850), Campinas: Editora Unicamp, 2005; Tâmis Parron, A política da escravidão no Império do Brasil, 1826-1865, Rio de Janeiro: Civilização Brasileira, 2011; e Beatriz Gallotti Mamigonian, Africanos livres: a abolição do tráfico de escravos no Brasil, São Paulo: Companhia das Letras, 2017.
Lorena Novais Almeida, mergulha em inventários post-mortem com traslado de testamentos, assentos notarias e ações de libelo cível para estudar experiências econômicas, havidas no comércio e na lavoura, formas de sociabilidade e relações familiares envolvendo mulheres libertas. A autora traça, ainda, um panorama da flutuação demográfica da região articulado às transformações da economia escravista, incluindo indicativos a respeito da incidência das alforrias sobre os grupos que compunham a população escrava. Em suas palavras, "distinguir a origem e a nação dos escravos naquele sertão é importante, pois as oportunidades de alforria não eram iguais para todos os escravos, inclusive os africanos". A autora destaca o investimento em escravos como traço comum do comportamento de diversos libertos e que isso por vezes remontava ao tempo de sua escravidão, isto é, aqui também fica patente a figura do escravo-senhor, o que remete o leitor ao caso de Víctor Chappotín do primeiro capítulo do livro. Contudo, Almeida destaca que a posse de escravos por escravos era algo precário, passível, eventualmente, de contestação. Segundo ela, a grande maioria dos cativos que chegaram a possuir escravos o fizeram para compor o pecúlio destinado à compra da liberdade.

Em seu conjunto, o livro evidencia que as dinâmicas das alforrias, as vivências dos egressos do cativeiro e as experiências que atavam o escravismo às formas de liberdade pelo 
continente afora foram marcadas por condicionalidades e incertezas; pelo estabelecimento de laços de clientela ou gratidão; bem como por limitações e possibilidades diversas. Ao mesmo tempo, os capítulos denotam importantes particularidades locais relacionadas às conjunturas históricas, à objetividade das condições materiais e aos contornos específicos das normas escritas e costumeiras vigentes nas diferentes jurisdições e territórios nacionais. O significado, o fundamento e a extensão de uma mesma circunstância como a do escravo-senhor, por exemplo, podiam ser sensivelmente distintos conforme o período e o local.

Em se tratando de uma coletânea, é quase impossível obter um equilíbrio pleno entre a abordagem dos autores. O capítulo sobre a Martinica, por exemplo, é excessivamente local, ladeado por dois capítulos que assumem um caráter marcadamente transnacional. A curiosidade do leitor é jogada na direção de fatores históricos ausentes do texto. Como as normas restritivas sobre alforria se encaixavam na tradição jurídica francesa mais antiga? Qual a repercussão da Revolução na França e em Saint-Domingue sobre as dinâmicas examinadas? De que maneira a política relativa às alforrias se articulava aos movimentos da economia marti- niquense e do tráfico transatlântico? Por que o governo francês instituiu todas aquelas restrições? Por que, efetivamente, a política se alterou em 1831? Tudo isso fica no ar.

Isso em nada desabona o livro ou o capítulo em questão, cujas excelentes contribuições já foram indicadas. O mais relevante é que a composição da obra e a apresentação dos organizadores acenam para algo mais do que um compêndio temático atualizado. $\mathrm{O}$ volume traz um auspicioso convite à superação das ênfases, mutuamente excludentes, na unidade ou na diversidade do escravismo atlântico, nas estruturas socioeconômicas ou na agência dos sujeitos históricos, acenando para uma agenda historiográfica renovada, atenta à complexidade das relações cotidianas, à pluralidade dos tempos históricos, à importância da perspectiva comparada e ao aprofundamento das investigações empíricas. Por fim, cabe notar que a identificação da existência de escravos e libertos eventualmente proprietários de escravos e/ou fieis a seus senhores e patronos não faz de nenhum trabalho historiográfico algo "politicamente incorreto". Tais constatações apenas demonstram a complexidade das relações escravistas e revela uma parcela das forças sistêmicas que garantiram a reprodução da escravidão nas Américas.

Waldomiro Lourenço da Silva Júnior Universidade Federal de Santa Catarina waldomiro.silva@ufsc.br 